\title{
Ocean Preconditioning of Cyclone Nargis in the Bay of Bengal: Interaction between Rossby Waves, Surface Fresh Waters, and Sea Surface Temperatures*
}

\author{
LISAN YU \\ Woods Hole Oceanographic Institution, Woods Hole, Massachusetts \\ MiCHAEL J. MCPHADEN \\ NOAA/Pacific Marine Environmental Laboratory, Seattle, Washington
}

(Manuscript received 22 January 2010, in final form 13 April 2011)

\begin{abstract}
An in-depth data analysis was conducted to understand the occurrence of a strong sea surface temperature (SST) front in the central Bay of Bengal before the formation of Cyclone Nargis in April 2008. Nargis changed its course after encountering the front and tracked along the front until making landfall. One unique feature of this SST front was its coupling with high sea surface height anomalies (SSHAs), which is unusual for a basin where SST is normally uncorrelated with SSHA. The high SSHAs were associated with downwelling Rossby waves, and the interaction between downwelling and surface fresh waters was a key mechanism to account for the observed SST-SSHA coupling.

The near-surface salinity field in the bay is characterized by strong stratification and a pronounced horizontal gradient, with low salinity in the northeast. During the passage of downwelling Rossby waves, freshening of the surface layer was observed when surface velocities were southwestward. Horizontal convergence of freshwater associated with downwelling Rossby waves increased the buoyancy of the upper layer and caused the mixed layer to shoal to within a few meters of the surface. Surface heating trapped in the thin mixed layer caused the fresh layer to warm, whereas the increase in buoyancy from low-salinity waters enhanced the high SSHA associated with Rossby waves. Thus, high SST coincided with high SSHA.

The dominant role of salinity in controlling high SSHA suggests that caution should be exercised when computing hurricane heat potential in the bay from SSHA. This situation is different from most tropical oceans, where temperature has the dominant effect on SSHA.
\end{abstract}

\section{Introduction}

Tropical Cyclone Nargis reached category-4 hurricane strength, causing the worst natural disaster in the recorded history of Myanmar (Webster 2008; McPhaden et al. 2009a). The cyclone struck the mouth of the Irrawaddy River on 2 May 2008 (Fig. 1) and devastated the region with peak winds of $65 \mathrm{~m} \mathrm{~s}^{-1}, 60 \mathrm{~cm}$ of rain, and a storm surge as much as $5 \mathrm{~m}$ high. More than 146000 lives were lost, and more than one million people became homeless.

* Pacific Marine Environmental Laboratory Publication Number 3710.

Corresponding author address: Dr. Lisan Yu, Department of Physical Oceanography, MS\#21, Woods Hole Oceanographic Institution, Woods Hole, MA 02543.

E-mail: lyu@whoi.edu
The tragic human cost from Cyclone Nargis underlines the long-standing vulnerability of the countries bordering the Bay of Bengal to natural disasters, a vulnerability that is compounded by dense population along geographically low-lying coastal areas and by poorly designed and supported disaster management strategies.

Nargis was first detected on 27 April in the middle of the Bay of Bengal. When superimposing the Nargis track onto the sea surface temperature (SST) field averaged over 24-26 April (Fig. 1a), one is struck by the apparent connection between a preexisting band of high SSTs and the storm path that occurred after 27 April. The preexisting SST front lay across the central Bay in a northeastsouthwest direction west of $87^{\circ} \mathrm{E}$, whereas east of $87^{\circ} \mathrm{E}$ it was oriented in a west-east direction perpendicular to the mouth of the Irrawaddy River. When the storm first encountered the high SST front at $12^{\circ} \mathrm{N}, 85^{\circ} \mathrm{E}$, it was heading northwest toward India. In the following $24 \mathrm{~h}$, 
(a)

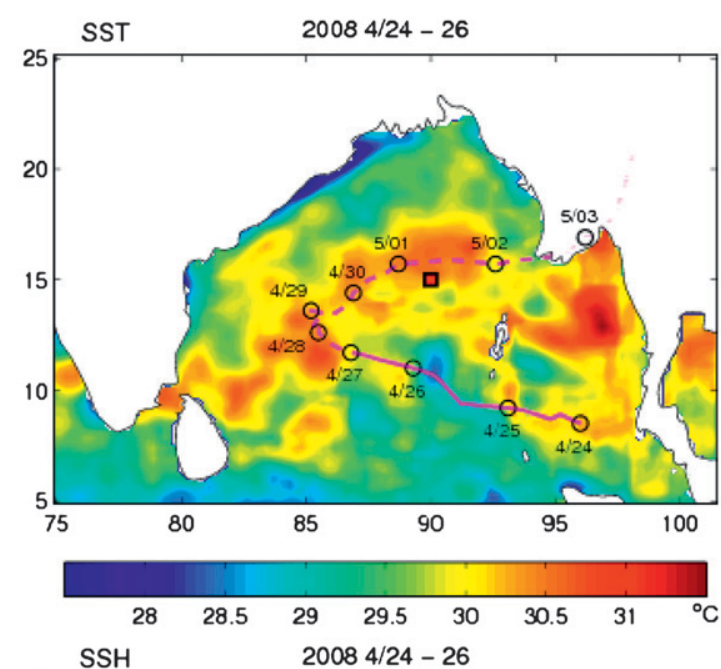

(b)

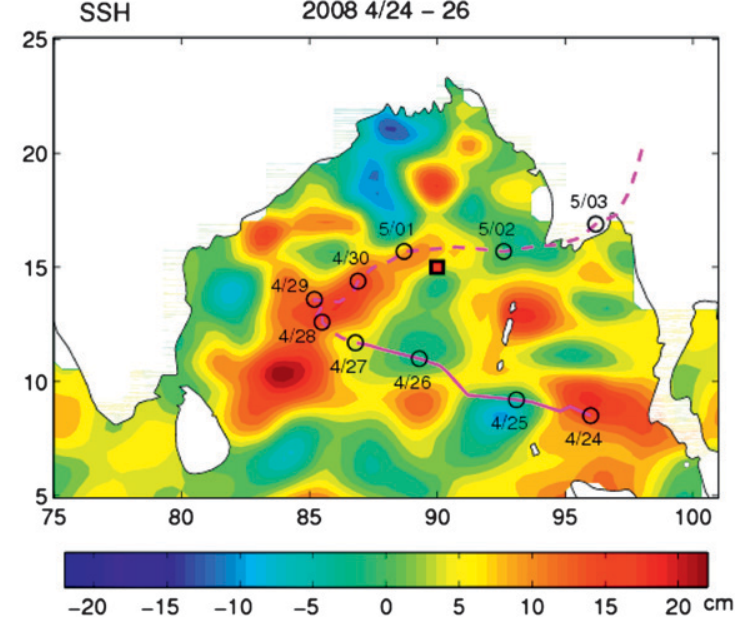

FIG. 1. (a) SST and (b) SSHA averaged over the three days 24-26 April 2008 before Cyclone Nargis became a severe storm. Track of Cyclone Nargis is represented by the magenta line. The part of solid line with open circle represents the cyclone path over the three days used in averaging SST and SSHA, and the dashed line denotes the cyclone path for the following days. The RAMA buoy at $15^{\circ} \mathrm{N}, 90^{\circ} \mathrm{E}$ is denoted by a black square with a red center.

the storm intensified rapidly and was upgraded from a tropical disturbance to a severe cyclonic storm (winds of 25-32 $\mathrm{m} \mathrm{s}^{-1}$ ) named Nargis. By 29 April, after remaining nearly stationary for about two days, Nargis weakened slightly and started to move eastward away from India. As it traveled in its new direction, the storm regained strength and followed the SST front all the way until it struck the low-lying Irrawaddy delta at peak intensity (equivalent to a category-4 hurricane) in the early morning of May 2. The apparent connection between the high SST front and Nargis's intensity and path suggests an active coupling between the cyclone and the warm ocean waters.

The mean SST pattern shown in Fig. 1a was constructed over the three days between 24 and 26 April, the period that Nargis was a tropical depression and yet to be named. The strong SST front lay between the warmest surface waters over the bay $\left(\mathrm{SST}>30^{\circ} \mathrm{C}\right)$ and slightly cooler surface waters $\left(\mathrm{SST}>28^{\circ} \mathrm{C}\right)$ that were nevertheless quite warm because April and May are the time of seasonal warming. The strong SST front was not merely a surface phenomenon. Satellite altimetric sea surface height ( $\mathrm{SSH}$ ) is an effective depth-integrated representation of the temperature and salinity (or collectively buoyancy) structure of the water column. The SSH anomaly (SSHA) field averaged over the same three-day period as that of SST (Fig. 1b) shows that the SST front was associated with a band of high SSHA oriented in a similar direction. The structural consistency between SST and SSHA indicates a tight coupling between the surface and subsurface waters.

However, the coupling between SST and SSHA in the Bay of Bengal is generally weak (Gopalan et al. 2000; Rao et al. 2002; Rao and Behera 2005) primarily because of the permanent highly stratified near-surface layer. Large freshwater influx from precipitation and river discharge causes a thin fresh layer to form at the surface, which affects the density stratification and the depth of vertical mixing (Vinayachandran et al. 2002). As a result, the mixed layer is usually shallow and determined by salinity stratification, whereas the isothermal layer depth is much deeper, resulting in a barrier layer (Godfrey and Lindstrom 1989; Lukas and Lindstrom 1991; Sprintall and Tomczak 1992). The barrier layer keeps the influence of atmospheric heat and momentum forcing predominantly in the surface mixed layer and meanwhile prevents the entrainment of the cooler thermocline waters from below. These dual effects impose a strong barrier to communication between the surface mixed layer and subsurface thermocline. This is the reason that SST in the bay is usually uncorrelated with SSHA. The apparent association between high SSTs and SSHAs before and during Cyclone Nargis suggests though that the SST-SSHA relationship can sometimes be governed by other mechanisms. We will show here that the interaction between downwelling Rossby waves and surface fresh waters is a key mechanism for coupling SST and SSHA in this case.

Understanding the ocean surface and subsurface coupling is important for understanding and predicting the intensity of tropical cyclones. Emanuel (1999) suggested three key factors control the intensity of tropical cyclones: namely, the initial intensity of the cyclone, the thermodynamic state of the atmosphere through which it moves, and the heat exchange with the upper layer of the ocean under the core of the cyclone. Interaction between the cyclone and the underlying ocean in particular plays a pivotal role, because the heat and 
moisture transfer from the warm ocean surface are the ultimate source of energy for a cyclone. The viewpoint is further supported by the fact that the cyclones rapidly intensify whenever they encounter warm-core rings in the oceans (Shay et al. 2000; Ali et al. 2007). In the Bay of Bengal, there are only three or four named tropical cyclones each year, which account for less than $5 \%$ of the annual total cyclone events worldwide (Alam et al. 2003). These few tropical storms, though they may not be the most intense storms on the Saffir-Simpson scale, have great potential for catastrophic impacts. Of the top 20 deadliest tropical cyclones in the world history, 14 were spawned in the Bay of Bengal, including Cyclone Nargis (Longshore 2008). Identifying the ocean conditions that are common for the formation of severe tropical storms over this highly stratified upper ocean would be of practical importance for improving cyclone intensity prediction in the bay and elsewhere.

There have been several case studies of Cyclone Nargis. McPhaden et al. (2009a) described the evolution of the cyclone and its effects on the ocean as captured by in situ-based Indian Ocean Observing System (IndOOS) and space-borne satellite sensors. Kikuchi et al. (2009) reported the role of the Madden-Julian oscillation (MJO) in cyclone initiation. Lin et al. (2009) identified abovenormal SST to be the cause of the rapid intensification just before Nargis made landfall in Myanmar. Yamada et al. (2010) suggested the importance of the subtropical jet as a determinant of cyclone track and intensification. Reale et al. (2009) found that new three-dimensional atmospheric data from the Atmospheric Infrared Sounder (AIRS) instrument on the National Aeronautics and Space Administration (NASA) Aqua satellite can improve the track forecast up to 4 days in advance by improving the position of the cyclone's center.

The present analysis focuses on oceanic conditions before and during Cyclone Nargis with emphasis on two questions prompted by observations: one is the cause of the preexisting strong SST front in the central bay and the other is the mechanism for SST and SSHA coupling within the front. This study is based on data analysis using observations acquired from moored buoys together with basin-scale Argo profiling floats and earth observing satellites. The presentation is organized as follows: A brief description of data is given in section 2. The association of the warm front with westwardpropagating Rossby waves is analyzed in section 3 . The mechanisms governing sea surface warming are studied in section 4. Cause of the enhanced surface warming along the band of high SSHA is examined in section 5, and the coupling between SST and high SSHA is delineated in section 6 . In section 7, the salinity effects on sea level variability are investigated using a hydrostatic relationship established from a 11/2-layer model. Discussion and summary are given in section 8 .

\section{IndOOS and satellite observations}

Ocean observations of the Bay of Bengal have been improved significantly in recent years thanks to continuing international efforts to implement the sustained IndOOS. IndOOS is in situ network-based, including Argo, XBT, and moored buoys (Meyers and Boscolo 2006). A key element of IndOOS is the Research Moored Array for African-Asian-Australian Monsoon Analysis and Prediction (RAMA) (McPhaden et al. 2009b), which consists of 46 moored buoys in the tropical sector and is the Indian Ocean equivalent of Tropical Atmosphere Ocean (TAO)/Triangle Trans-Ocean Buoy Network (TRITON) in the tropical Pacific and Prediction and Research Moored Array in the Tropical Atlantic (PIRATA) in the tropical Atlantic. At the time that Cyclone Nargis occurred, the buoy array in the Bay of Bengal was already functioning. In particular, the northernmost buoy $\left(15^{\circ} \mathrm{N}, 90^{\circ} \mathrm{E}\right)$ of the array (Fig. 1), which began reporting data on 18 November 2007, was centered on the storm track when the storm passed by in 2008 , yielding a time series of the upper-ocean temperature, salinity, and related air-sea conditions (including wind, near-surface air humidity and temperature, surface incoming solar and longwave radiation, and sea level pressure) around the time of the storm (McPhaden et al. 2009a). Together with a constellation of earth observing satellites that provides continuous global monitoring of key air-sea parameters such as winds, SST, SSHA, etc., Nargis has been so far one of the best observed storm events in the Bay of Bengal.

Tropical storms in the Bay of Bengal occur predominantly before and after the southwest monsoon in April-May and October-November, when SSTs are at their seasonal maximum and vertical wind shear is weak, the two conditions necessary for the cyclone development (Gray 1979). Nargis was the first named tropical cyclone in the 2008 cyclone season of the north Indian Ocean. The RAMA buoy at $15^{\circ} \mathrm{N}, 90^{\circ} \mathrm{E}$ was initially deployed in midNovember 2007, thus providing a unique opportunity for understanding the oceanographic conditions before and during Cyclone Nargis. To complement the buoy time series analysis, basin-scale observations are used that include not only SST and SSHA but also salinity and precipitation. The salinity product is gridded from Argo profiling floats on a monthly basis (Hosoda et al. 2008), and the precipitation dataset is the Global Precipitation Climatology Project (GPCP) daily analysis (Huffman et al. 2001). SST data are taken from the daily SST analysis of Advanced Very High Resolution 
Radiometer (AVHRR), Tropical Rainfall Measuring Mission (TRMM), and AMSR-E (Reynolds et al. 2007). The altimeter data comprise a weekly repeat cycle compiled from the Ocean Topography Experiment (TO$\mathrm{PEX}) /$ Poseidon (T/P) and Jason-1 missions with $1 / 3^{\circ}$ spatial resolution (AVISO 2009).

\section{Association of the warm front with westward-propagating Rossby waves}

By examining satellite SSHA observations and RAMA buoy measurements at $15^{\circ} \mathrm{N}, 90^{\circ} \mathrm{E}$, it appears that the preexisting SST front across the central Bay of Bengal (Figs. 1a,b) was a transient originating from the eastern boundary. To corroborate the two sets of observational evidence, the SSHA variability along the buoy latitude at $15^{\circ} \mathrm{N}$ is plotted to show the signal propagation (Fig. 2). It can be seen that the positive SSHA in the central basin in April 2008 can be traced back to the Andaman Sea (viz., the eastern extension of the Bay of Bengal) in December 2007. The positive SSHA signal propagated westward with a speed of roughly $9 \mathrm{~cm} \mathrm{~s}^{-1}$, comparable to the phase speed of first baroclinic Rossby waves (Yang et al. 1998). Amplitude of the waves was more pronounced after the signal passed the Andaman and Nicobar Islands (i.e., the chain of islands along the longitude $\sim 92^{\circ} \mathrm{E}$ in Fig. 1) into the interior of the bay.

Rossby waves propagating westward from the eastern boundary are featured throughout the time-longitude plot (Fig. 2). Predominant negative SSHAs (associated with upwelling Rossby waves) were observed between September 2007 and January 2008, whereas positive SSHAs (associated with downwelling Rossby waves) were noted in the open bay after February 2008. The marked seasonal reversal of SSHA in the Bay of Bengal has been reported in previous studies (Yang et al. 1998; Eigenheer and Quadfasel 2000), which was attributed to both local wind forcing and the remote forcing from the equatorial region (Yu et al. 1991; Potemra et al. 1991; McCreary et al. 1993). The seasonal variation of SSHA in 2007-08 is consistent with the climatological seasonal pattern in the region (e.g., Yang et al. 1998).

It has been known that Rossby waves propagating away from the eastern boundary can be attributable to both local alongshore monsoon winds and remote forcing through radiation of coastal Kelvin waves that propagate from the equator (Yu et al. 1991; Potemra et al. 1991; McCreary et al. 1993; Girishkumar et al. 2011). Large-scale forcing associated with monsoon winds excite eastward-propagating Kelvin waves along the equator. Upon arriving at the eastern boundary, some of the wave energy is reflected back to the

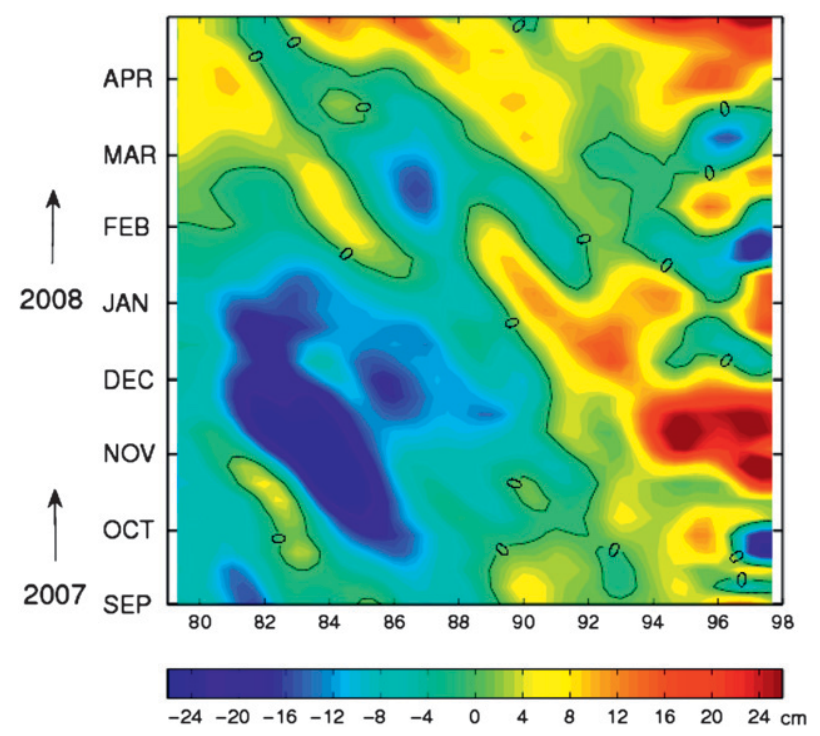

FIG. 2. Time-longitude plot of 7-day mean SSHA along $15^{\circ} \mathrm{N}$, which is the latitude of the northernmost RAMA buoy.

equatorial waveguide as Rossby waves and the remaining energy is carried poleward along the eastern periphery as coastally trapped Kelvin waves (Moore 1968). Along the pathway of the coastal Kelvin waves, Rossby waves are radiated, which propagate westward away from the boundary and influence the circulation in the ocean interior. The local wind-driven circulation in the ocean interior is enhanced (weakened or reversed) if the waves are in the same phase as (opposite to) local wind stress curl. The dominant role of remote equatorial waves in seasonal wind-driven circulation of the Bay of Bengal has been studied extensively using numerical models and satellite SSHA observations (McCreary et al. 1993; Vinayachandran et al. 1996; Yang et al. 1998; Eigenheer and Quadfasel 2000; Yu 2003). We have examined the respective roles of local and remote forcing in generating the band of high SSHA in the central bay using a linear reduced gravity model forced by QuikSCAT winds. The model simulations (not shown) showed that the coastal downwelling Kelvin waves originating from the equatorial oceans were the predominant forcing for the high SSHA in the central bay. Local wind forcing was in phase with the remote signal, but the amplitude was too weak to be significant.

The positive SSHA in association with the downwelling Rossby waves were most pronounced during March and April 2008 (Fig. 2). To examine the spatial structure of SSHA during the westward propagation, weekly-mean SSHA fields at three different periods between March and April are shown (Figs. 3a-c). The buoy location at $15^{\circ} \mathrm{N}, 90^{\circ} \mathrm{E}$ is superimposed as a fixed reference for the waves' motion. For the SSHA field centered on 1 March 
2008, there was a band of positive SSHA lying across the bay, with the northern end in the neighborhood of the mouth of the Irrawaddy River and the southern end extending into the southern tip of peninsular India and Sri Lanka. The buoy location at $15^{\circ} \mathrm{N}, 90^{\circ} \mathrm{E}$ was on the northwestern edge of the band. Four weeks later, on 29 March 2008, the band of positive SSHA has evidently widened and strengthened. Slight westward displacement is visible, because the buoy location was now in the middle of the band. For a wave speed of $\sim 9 \mathrm{~cm} \mathrm{~s}^{-1}$, Rossby waves would have propagated about $160 \mathrm{~km}$ $\left(\sim 1.4^{\circ}\right)$ westward in the previous 21 days and would be further westward by about $220 \mathrm{~km}\left(\sim 2^{\circ}\right)$ over the next 4 weeks. The buoy location provides a good reference for the continuing westward movement of downwelling Rossby waves. By 19 April 2008, the majority of the positive SSHA band had passed the RAMA buoy location.

The near-surface circulation and upper-ocean temperature/salinity structure associated with the downwelling Rossby waves were well captured by the moored buoy instruments at $15^{\circ} \mathrm{N}, 90^{\circ} \mathrm{E}$. The daily time series of the near-surface currents measured at $10 \mathrm{~m}$ (Fig. 4) shows flow in the northeastward direction from midFebruary to mid-March 2008, changing into predominantly a southwestward flow thereafter, and persisted throughout April 2008. The observed anticyclonic circulation during the passage of the high SSHA band is consistent with the circulation pattern due to downwelling Rossby waves.

\section{Mechanism governing the sea surface warming}

During downwelling, SST does not necessarily increase with high SSHA, because the convergence of surface water to the subsurface is not a source of heating. Upwelling is different, because it draws cooler water from the subsurface to the surface and, through mixing processes, lowers SST. This asymmetry in how the ocean responds to upwelling and downwelling velocities raises the question of what caused the high SSTs along the band of positive SSHA in association with downwelling Rossby waves in the open bay (Figs. 1a,b)? Here we examine this issue using the buoy observations.

Climatologically, SSTs in the Bay of Bengal are at seasonal maximum during the spring transition season (March-May) because of the combined effects of high incoming solar radiation and weak winds (Schott and McCreary 2001). The RAMA buoy at $15^{\circ} \mathrm{N}, 90^{\circ} \mathrm{E}$ is designed as a "flux-reference site" (McPhaden et al. $2009 \mathrm{~b}$ ) and is equipped with a complete suite of sensors to provide measurements of air-sea heat exchange, including solar radiation, longwave radiation, latent heat flux, and sensible heat flux. The residual of these
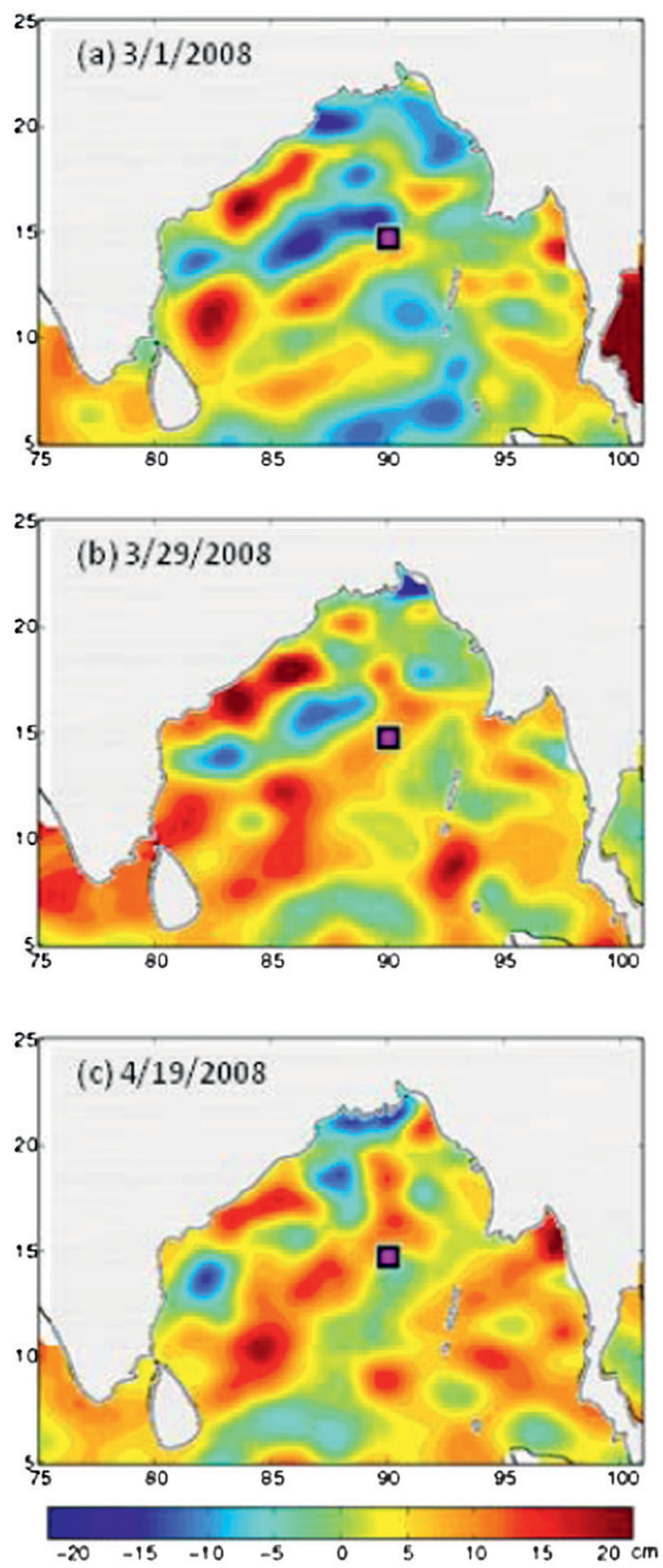

FIG. 3. The 7-day mean SSHA field centered on (a) 1 Mar, (b) 29 Mar, and (c) 19 Apr 2008. The black square with a purple center denotes the $15^{\circ} \mathrm{N}, 90^{\circ} \mathrm{E}$ buoy location. 


\section{Daily Data}
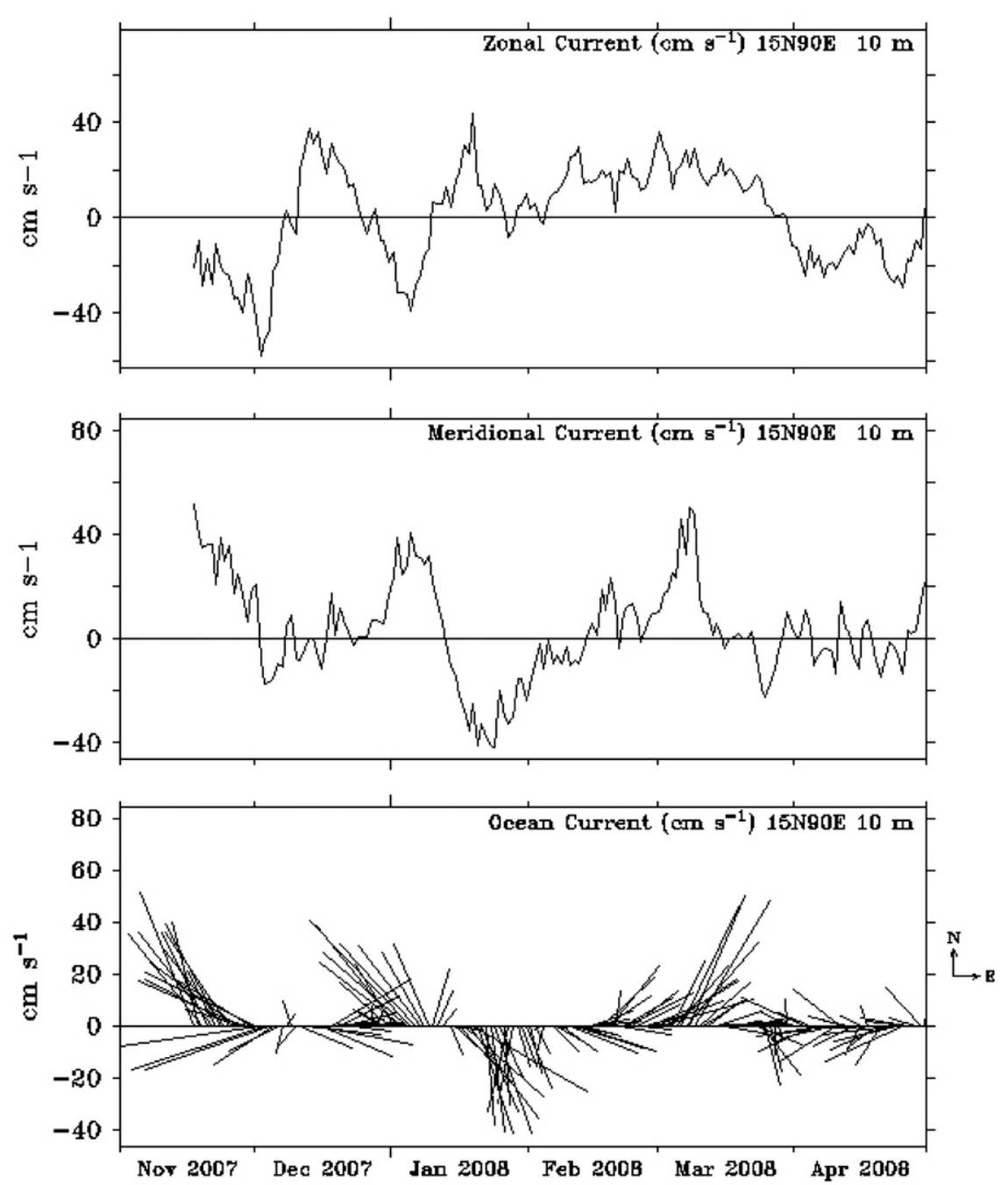

FIG. 4. Daily time series of near-surface current at the depth of $10 \mathrm{~m}$ from RAMA buoy measurements at the $15^{\circ} \mathrm{N}, 90^{\circ} \mathrm{N}$ location.

heat exchange processes is the net heat flux, which is denoted by $Q_{\text {net }}$. Figures 5a,b are time series of buoy measurements of daily-mean $Q_{\text {net }}$ and SST over the 5 months from 18 November 2007 (the start of the buoy time series) to 30 April 2008 (one day before Cyclone Nargis struck the buoy location). The time series show that the ocean received net heat from the atmosphere (i.e., downward $Q_{\text {net }}$ is positive) in March-April 2008; at the same time, the ocean surface warmed up by more than $3^{\circ} \mathrm{C}$, from near $27^{\circ} \mathrm{C}$ in early March to greater than $30^{\circ} \mathrm{C}$ in late April.

The change of SST, denoted by $\partial \mathrm{SST} / \partial t$, is related to $Q_{\text {net }}$ through the heat budget equation, $\partial \mathrm{SST} / \partial t=$ $Q_{\text {net }} /\left(\rho c_{p} h\right)+$ other terms (e.g., advection, entrainment, and diffusion), where $\rho$ is the density of seawater, $c_{p}$ is the heat capacity of seawater, and $h$ is the mixed layer depth (MLD) derived from buoy subsurface measurements (Fig. 6). Thus, variability of $\partial \mathrm{SST} / \partial t$ can be approximated once $Q_{\text {net }}$ is known, assuming other terms are small. Daily time series of $\partial S S T / \partial t$ predicted by this simple relation are compared with the observed $\partial \mathrm{SST} / \partial t$ in Fig. 5c. The good agreement between the modeled and observed $\partial S S T / \partial t$ during March-April 2008 suggests that the increase of SST was controlled primarily by local surface heating $Q_{\text {net }}$ with a variable MLD. This finding is consistent with the previous study of Sengupta and Ravichandran (2001) of $\partial S S T / \partial t$ in the bay. We show in the following that the thinning of the MLD during March-April played an important role for $Q_{\text {net }}$ as the effective mechanism for near-surface temperatures. 
(a)

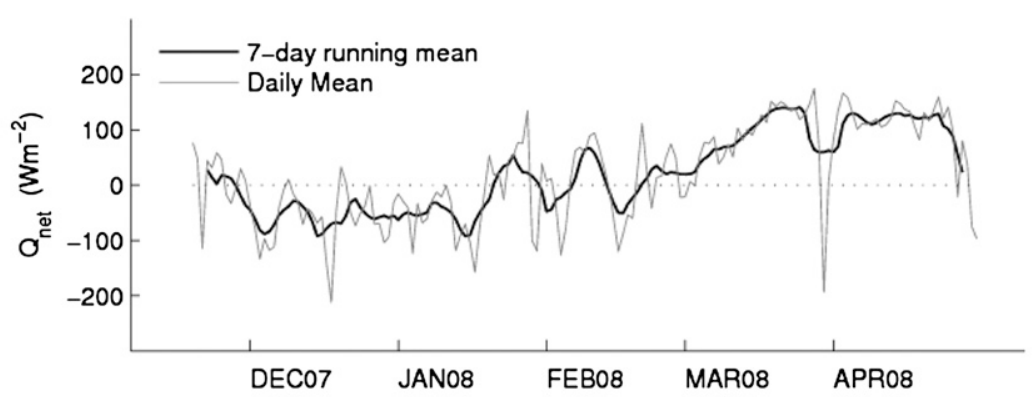

(b)

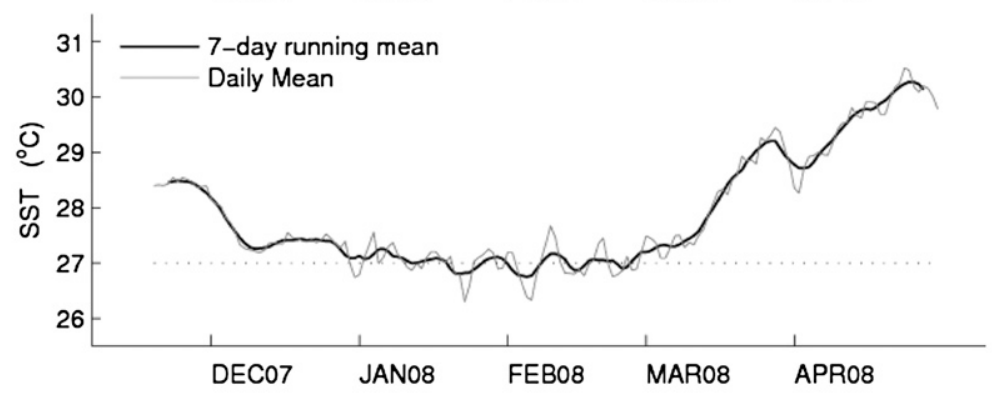

(c)

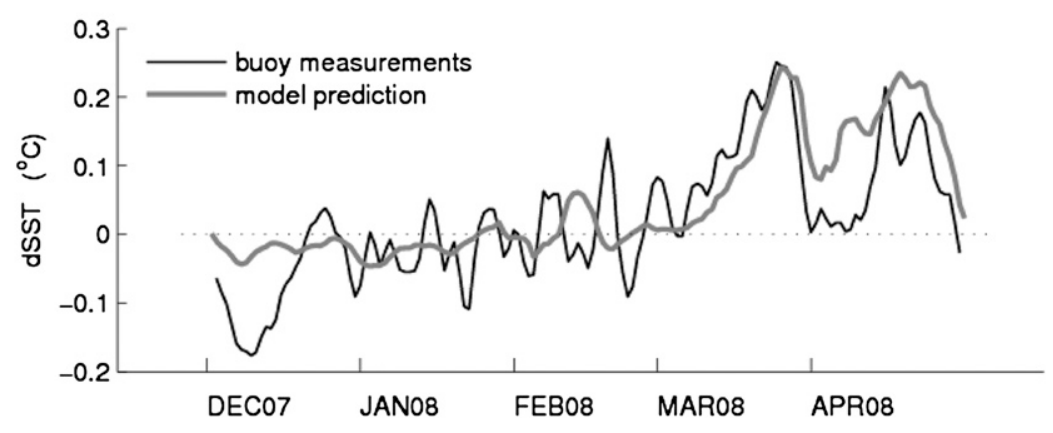

FIG. 5. Daily time series of (a) buoy $Q_{\text {net }}$, (b) buoy SST, and (c) $\partial S S T / \partial t$ from model prediction and buoy measurements. All are constructed at the $15^{\circ} \mathrm{N}, 90^{\circ} \mathrm{E}$ buoy location.

MLD is computed from the density profiles derived from buoy temperature and salinity. Because of the influence of the near-surface fresh layer on the vertical density profile in the Bay of Bengal, the densitydependent MLD is different from the isothermal layer depth (ILD) determined from a temperature criterion. The distance separating the MLD and ILD is called the barrier layer because of its effect on the mixed layer heat budget (Godfrey and Lindstrom 1989; Lukas and Lindstrom 1991; Sprintall and Tomczak 1992). Here, the MLD is defined as the depth at which the density change from the ocean surface corresponding to a temperature change of $0.5^{\circ} \mathrm{C}$ (Sprintall and Tomczak 1992), and the ILD is defined as the depth at which the temperature falls to $0.5^{\circ} \mathrm{C}$ below the surface temperature. Figures $6 a, b$ show the time-depth sections of daily-mean potential temperature, salinity, and potential density $\sigma_{t}$ $(=\rho-1000)$ for the upper $140 \mathrm{~m}$ over the 5-month observing period, with daily time series of the MLD and ILD superimposed. The depths of the $26^{\circ} \mathrm{C}$ isotherm
(D26), the 34.2-psu isohaline, and the $22.4 \mathrm{~km} \mathrm{~m}^{-3}$ isopycnal are highlighted in the respective plots. These isodepths are located at the top of the thermocline/ halocline/pycnocline and vary between 70 and $90 \mathrm{~m}$ throughout most of the data record.

Marked changes in the MLD and ILD are noted in two periods. The months from December 2007 to early March 2008 are, by definition, the winter monsoon season. In this period, the difference between the MLD and ILD was large, so the BLT was thick $(\sim 40 \mathrm{~m})$. The ILD was located at the bottom of the near-surface warm layer at a depth mostly below $60 \mathrm{~m}$, and it correlated well with the D26. Meanwhile, the MLD remained mostly in the upper $20 \mathrm{~m}$, though it sometimes plunged down to $40 \mathrm{~m}$ during synoptic weather events. The following months from mid-March to the end of April 2008 are the typical spring transition season. During this period, both the MLD and ILD became shallow and the difference between the two depths was small. The MLD was often less than $5 \mathrm{~m}$ deep, and the ILD shoaled significantly to close 

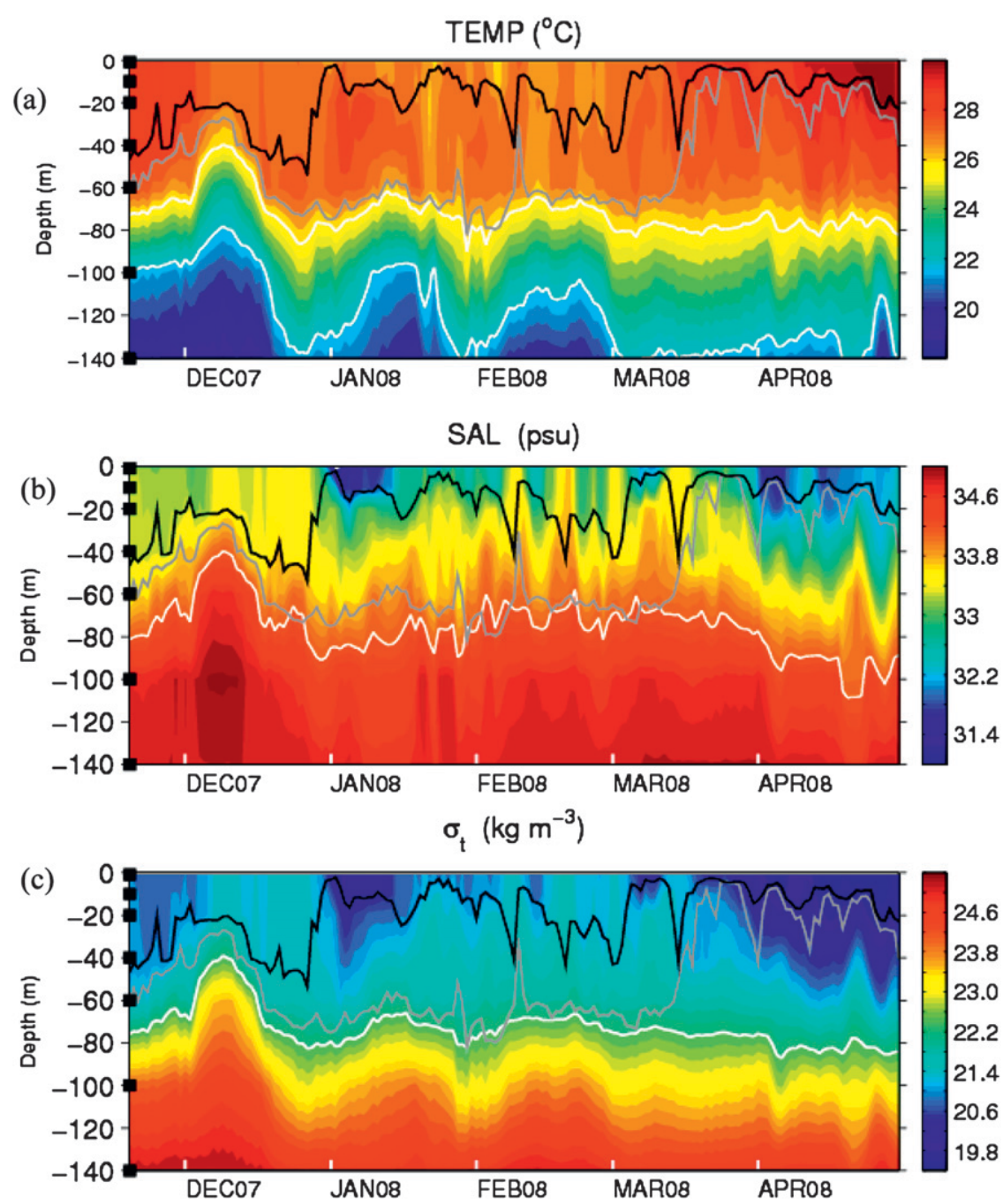

FIG. 6. Time-depth sections of daily-mean (a) potential temperature, (b) salinity, and (c) $\sigma_{t}$ derived from buoy measurements at $15^{\circ} \mathrm{N}, 90^{\circ} \mathrm{E}$. The thick black line denotes the MLD and the thick gray line denotes the ILD. The white lines denote the $22^{\circ}$ (lower) and the $26^{\circ} \mathrm{C}$ (upper) isotherms in (a), the 34.2-psu isohaline in (b), and the $22.4 \sigma_{t}$ isopycnal in (c).

to the MLD. Thus, the BLT was thin and, in some days, disappeared. The BLT as revealed from the $15^{\circ} \mathrm{N}, 90^{\circ} \mathrm{E}$ buoy measurements increased in the winter and decreased during the spring transition season, consistent with the basin-wide climatological analysis of multiyear Argo profiling floats (Thadathil et al. 2007) and mooring data (Girishkumar et al. 2011).

Changes of SST depend strongly on the mixed layer processes, particularly the interplay between kinetic energy and potential energy in determining the MLD. During the spring transition period (March-April), winds are weak and net heat flux is downward (Yu et al. 2007), so the MLD was controlled largely by one-dimensional heating processes (Rao and Sivakumar 1996; Sengupta and Ravichandran 2001). Sustained downward net heating during March-April 2008 was observed at the buoy location (Fig. 5a). The shallow mixed layer allowed the net heat flux to be distributed over a thin layer and caused the layer temperature to rise (Fig. 5b) as the result of the dominance of $Q_{\text {net }}$ in $\partial \mathrm{SST} / \partial t$ (Fig. 5c). By comparison, $Q_{\text {net }}$ and $\partial \mathrm{SST} / \partial t$ were less correlated before March, a period that $Q_{\text {net }}$ remained slightly negative (i.e., heat was released from the ocean surface to the atmosphere), except for a few intraseasonal events.

\section{Cause of the enhanced surface warming along the band of high SSHA}

The spring warming is a distinct feature in the Bay of Bengal (Rao and Sivakumar 1996; Sengupta et al. 2002). 
However, why was the warming enhanced along the band of high SSHA? We discuss below the important role of salinity and downwelling in this observed phenomenon.

At the $15^{\circ} \mathrm{N}, 90^{\circ} \mathrm{E}$ buoy site, the surface waters during March-April 2008 experienced not only significant warming but also profound freshening (Figs. 6a,b). The surface waters registered a temperature above $30^{\circ} \mathrm{C}$ and salinity below $31.5 \mathrm{psu}$, which represent a $3^{\circ} \mathrm{C}$ increase in temperature and a 2-psu decrease in salinity during the two months. The relative importance of the effect of freshening versus the effect of warming on surface density can be measured by the density ratio, which is defined as $R_{\rho}=-\alpha \Delta T / \beta \Delta S$, where $\alpha$ is the thermal expansion coefficient; $\beta$ is the haline contraction coefficient of seawater; and $\Delta T$ and $\Delta S$ are the changes in surface temperature and salinity, respectively. If $R_{\rho}$ is greater than 1 , the temperature change is a dominant component of the density profile, whereas, if $R_{\rho}$ is less than 1 , salinity dominates. Over the 2-month warming period, $R_{\rho}$ ranged between 0.66 and 0.70 , indicating that the low salinity in the surface layer impacted the surface density more than the high temperature. Thus, salinity had a larger control on the MLD, which shoaled to within a few meters of the surface, trapping surface heat fluxes and causing warming in a thin fresh layer.

There are two possibilities that led to the freshening in the surface layer at the buoy site. One is precipitation and the other is the convergence of runoff-induced lowsalinity surface waters by downwelling Rossby waves. During the winter monsoon and the follow-on spring transition seasons, the Bay of Bengal, particularly the northern basin, is usually dry with low rainfall amounts. Daily rain-rate time series derived from satellite TRMM for the $15^{\circ} \mathrm{N}, 90^{\circ} \mathrm{E}$ buoy location from November 2007 to April 2008 (Fig. 7a) shows that, except for two major episodes (i.e., one in mid-November 2007 and the other in early March 2008), rain events were short lived, weak, and infrequent. An integrated view of the basin-wide precipitation pattern is provided in Figs. $7 \mathrm{~b}$,c, showing the monthly-mean precipitation in April 2008 and also the mean averaged precipitation over the entire 6 months. Low precipitation is observed in the northern bay (north of $14^{\circ} \mathrm{N}$ ), with average rain rate of less than $3 \mathrm{~mm}$ day ${ }^{-1}$ over the entire period. In April 2008, before Cyclone Nargis struck, the northern bay was mostly free of rain, with near zero rain rate averaged over the month. The limited amount of freshwater flux at the ocean surface was not sufficient to drive the sustained freshening event in March-April 2008.

The other possible source of the upper-layer freshening is the convergence of low-salinity surface waters by downwelling. The surface salinity in the Bay of Bengal exhibits a strong meridional gradient, with salinity lowest in the north and highest in the south (Figs. 8a,b) (Varkey et al. 1996; Shetye et al. 1996; Han and McCreary 2001). The fresh layer in the northern bay results from river runoff, including the Ganges-Brahmaputra and the Irrawaddy Rivers, which are the two largest rivers in the bay. Freshening of the sea surface in the northern bay is controlled predominantly by the freshwater inflows from rivers and is not correlated with precipitation (Figs. 7,8 ), because the latter was near zero over the target period. River discharge is largest during June-October and weakest in January-April (Yaremchuk et al. 2005). Once river runoffs tapered off after October 2007, salinity started to increase. This is observed when comparing the Argo salinity field at a depth of $10 \mathrm{~m}$ averaged over two time frames: one is the monthly-mean for April 2008 and the other is the average over the 6-month period from November 2007 to April 2008 (Figs. 8a,b). The meridional salinity gradient is seen to have weakened with time, because the north-south contrast in surface salinity decreased to 2 psu in April 2008 compared to 3.5 psu over the entire 6-month period. By April 2008, the surface waters were fresher in the northeast and saltier in the southwest.

The $15^{\circ} \mathrm{N}, 90^{\circ} \mathrm{E}$ buoy recorded two major freshening events in the surface layer over the 6-month period: one in January 2008 and the other in March-April 2008 (Fig. 6b). These two events were under the influence of downwelling Rossby waves (Fig. 2), and westward and/ or southward flow components associated with the passage of the anticyclonic circulation are observed (Figs. $4 a-c)$. Surface currents from these directions advect low-salinity waters from the northeast and freshened the surface waters at the buoy location. Downwelling converged the fresher surface waters into the subsurface layer, causing the buoyancy of the upper layer to increase. As a result of the stabilizing effect of the salinity profile, the mixed layer shoaled to within a few meters of the surface, trapping the surface heating to the thin mixed layer and causing the temperature to increase.

The existence of horizontal salinity gradient (Fig. 7b) is an important background in this mechanism. Given the lack of rainfall variability (Fig. 7a), advection of fresher surface water to the buoy site by currents (Fig. 4 ) is a logical source of surface freshening. Downwelling converged the fresh waters to the subsurface, which further enhanced the effect of low salinity on the upperlayer density profile and, together with the surface heating at that time (Fig. 5a), affected the MLD (Fig. 6) and SST (Figs. 5b,c).

\section{Coupling between SST and high SSHA}

It can be seen from the time series of SST and satellite SSHA at the $15^{\circ} \mathrm{N}, 90^{\circ} \mathrm{E}$ buoy site (Fig. 9) that high 
(a)

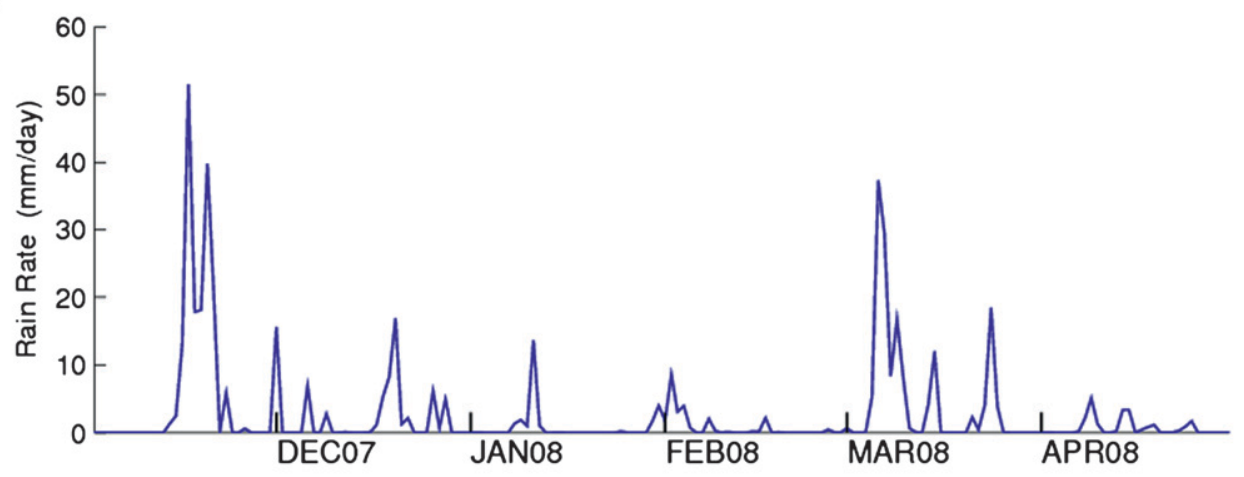

(b)

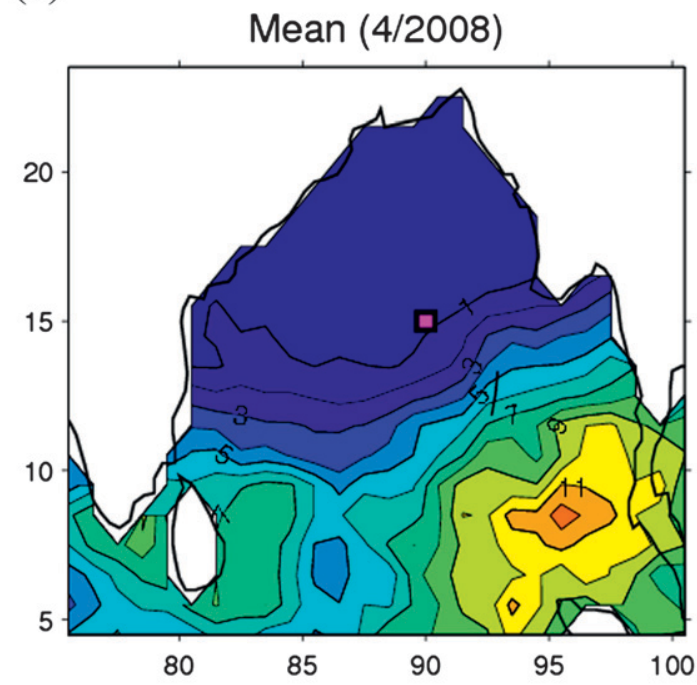

(c)

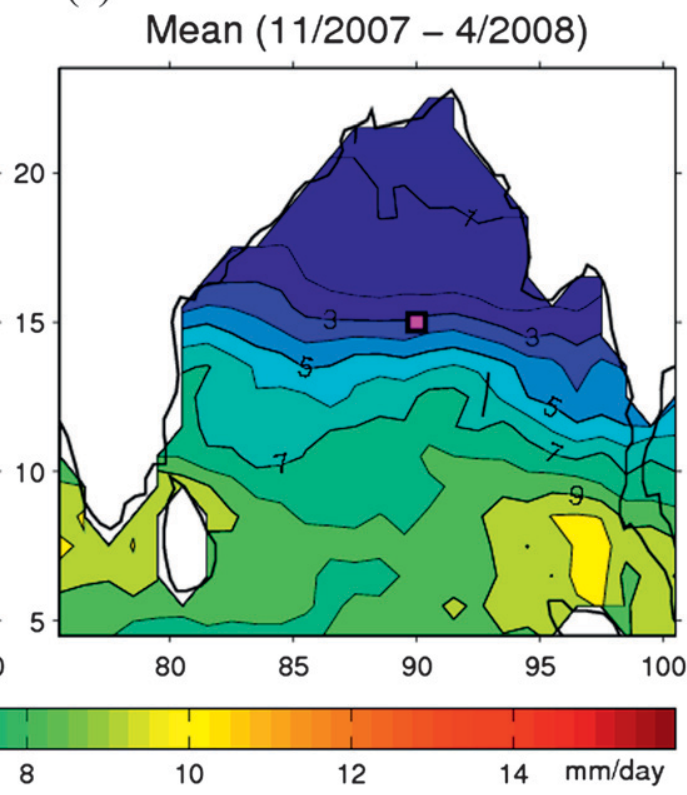

FIG. 7. (a) Daily time series of rain rate at $15^{\circ} \mathrm{N}, 90^{\circ} \mathrm{E}$, (b) mean rain rate in April 2008, and (c) mean rain rate averaged over the 6-month period November 2007-April 2008. The field maps in (b) and (c) are from GPCP. The black square with a purple center denotes the $15^{\circ} \mathrm{N}, 90^{\circ} \mathrm{E}$ buoy location.

SSHA were not always correlated with high SSTs. For instance, when downwelling Rossby waves passed the buoy site in December 2007 (Fig. 2), high SSHAs were detected and a freshening of the near-surface layer occurred (Fig. 6b), but SST did not increase. Based on the analysis in sections 4 and 5, the mechanism governing the high SSHA was the convergence of low-salinity surface waters by downwelling, which caused the increase of buoyancy and hence the increase of SSHA. On the other hand, the mechanism governing the change of SST was the net heat flux at the ocean surface.

During the two high SSHA events (one in December 2007 and the other in March-April 2008), similar oceanographic conditions were presented at the buoy site because both were associated with the propagation of downwelling Rossby waves and the freshening of the near-surface layer. However, the sign of the surface heat flux was opposite in these two cases. The ocean surface gained heat by $\sim 100 \mathrm{~W} \mathrm{~m}^{-2}$ in March-April 2008 but lost heat by $\sim 50 \mathrm{~W} \mathrm{~m}^{-2}$ in December 2007 (Fig. 5a). Although the mixed layer was shallow in both cases, a cooling of the sea surface was resulted in the December event when the ocean lost heat, causing the SST to be uncorrelated with the high SSHA. Conversely, a warming of the sea surface was observed in March-April, when the ocean gained heat, leading to high SSTs and a good correlation with high SSHA.

This study focuses on the relationship between SST and SSHA associated with downwelling Rossby waves. Their relationship in the case of upwelling Rossby waves 


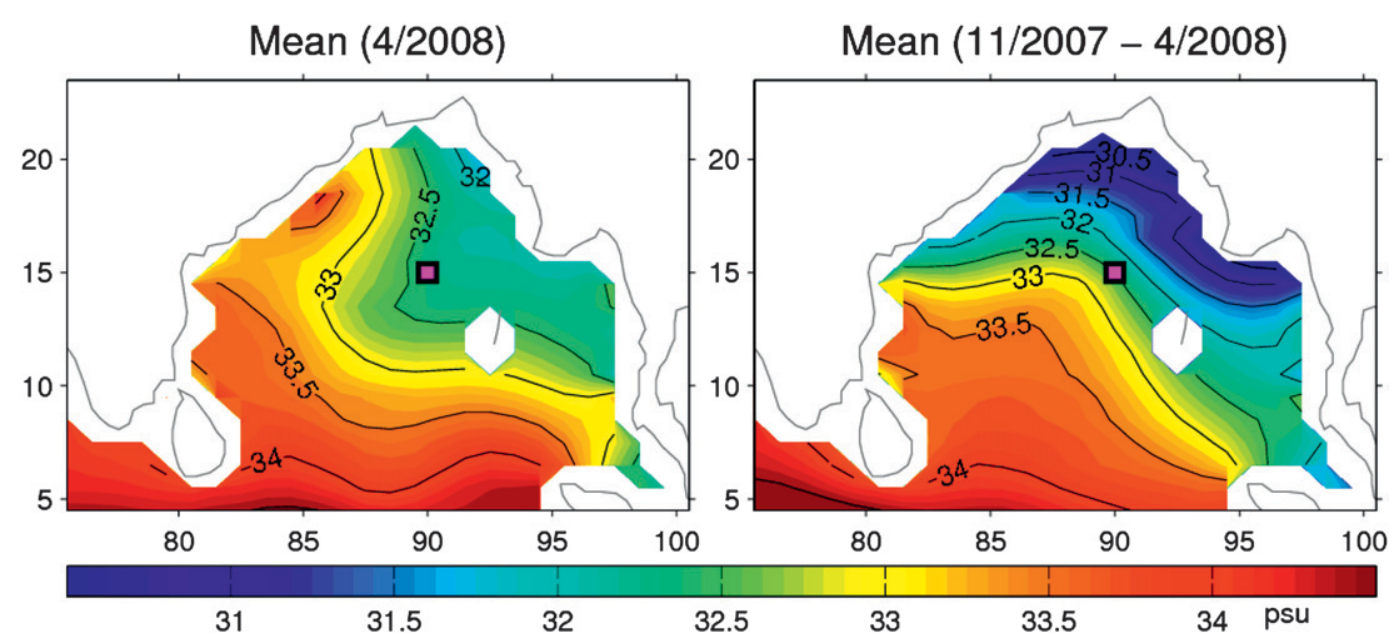

FIG. 8. Surface salinity at $10 \mathrm{~m}$ compiled from Argo profiling floats: (a) monthly mean for April 2008 and (b) the 6-month mean from November 2007 to April 2008. The black square with a purple center denotes the $15^{\circ} \mathrm{N}, 90^{\circ} \mathrm{E}$ buoy location.

was examined for the 1997 Indian Ocean dipole (IOP) event (e.g., Rao et al. 2002), which showed that there were no cold SST anomalies when SSHA was low. Thus, the correlation between SST variability and SSHA is often low or negative, regardless of whether the propagating Rossby waves are downwelling (positive SSHA) or upwelling (negative SSHA). The coexistence of high SST and high SSHA before Cyclone Nargis was unusual, which may reflect the coincidental occurrence of two seasonalrelated forcings (i.e., heating and downwelling) in the presence of a pronounced horizontal salinity gradient.

We have identified the respective mechanisms for the high SSHA and high SSTs in the bay. The two mechanisms are intrinsically linked when they are considered from the perspective of the low-salinity controlled vertical density profile. The direct effects of a low-salinity surface layer on the vertical density profile include the strong near-surface stratification and a shallow MLD. The strong salinity stratification inhibits vertical mixing across the pycnocline and essentially separates the processes in the thin mixed layer from the influence of subsurface. Consequently, the change of SST is governed predominantly by atmospheric heat flux at the sea surface. On the other hand, SSH is a depth-integrated representation of the vertical density profile and is sensitive to changes in the depth of the pycnocline caused by either temperature or salinity effect. Compared to the high temperature, the low salinity of the near-surface layer has a larger effect on the buoyancy of the upper layer, which imposed the primary control of the deepening of the pycnocline and the increase of SSHA (Fig. 6).

\section{Dominance of low salinity in buoyancy and SSHA}

The dominance of a low-salinity surface layer in causing high SSHA is elucidated in the above sections. This issue is further examined here by quantifying the relative contributions of salinity versus temperature to the buoyancy content and sea level variability. We first used buoy measurements to compute heat content $\left(\mathrm{HC}=\int_{0}^{z_{0}} c_{p} \rho T d z\right)$, salt content $\left(\mathrm{SC}=\int_{0}^{z_{0}} S d z\right)$, and buoyancy content $\left(\mathrm{BC}=\int_{0}^{z_{0}} g\left(\rho_{0}-\rho\right) / \rho_{0} d z\right.$, where $g$ is the gravity and $\rho_{0}$ is the density at the reference depth $z_{0}$ ) (Fig. 10). The reference depth is taken at $z_{0}=140 \mathrm{~m}$, which is the maximum depth of salinity sensors. Buoyancy represents the stratification of the water column. During the passage of downwelling Rossby waves in March-April 2008, HC increased only slightly, despite a $\sim 3^{\circ} \mathrm{C}$ warming in the thin mixed layer, whereas SC had a major reduction due to the reduction in salinity.

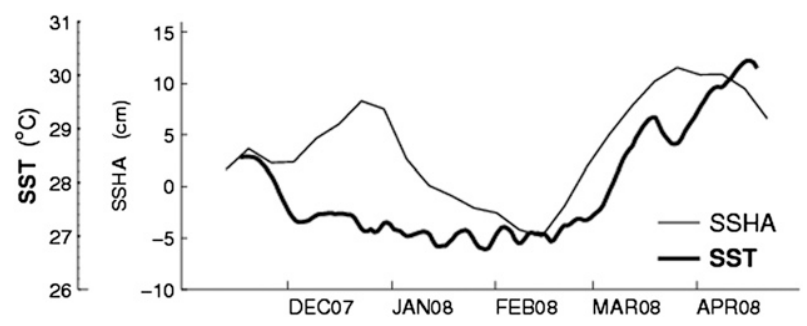

FIG. 9. Time series of 7-day mean SSHA superimposed with daily buoy SST (7-day running mean applied). An increase of SST was observed during the high SSHA event in March-April 2008 but did not occur during the high SSHA event in December 2007. 

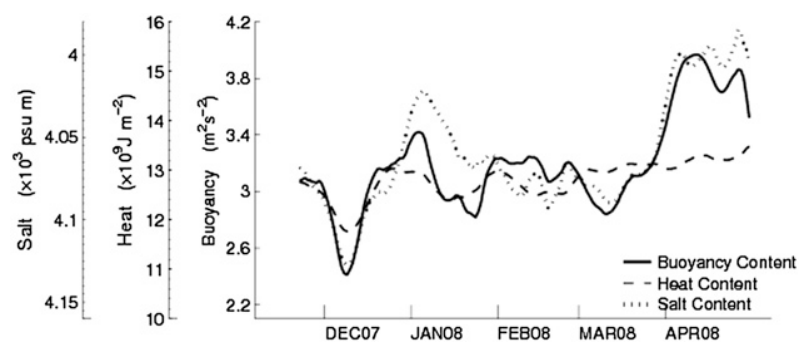

FIG. 10. Time series of buoyancy content, heat content, and salt content integrated from the surface to the depth of $140 \mathrm{~m}$. Note that the $y$ axis for salt content (blue) is reversed to emphasize the correlation between the increase of buoyancy and the decrease of salt content.

Throughout the time series, BC correlates highly with SC, indicative of the primary role of salinity in controlling the stratification of the warm and fresh surface layer in the Bay of Bengal.

That $\mathrm{BC}$ is related more to $\mathrm{SC}$ and less to $\mathrm{HC}$ has important implications for understanding the cause of SSHA variability in the Bay of Bengal. This situation is a striking contrast to the widely known relationship between SSHA and the thermocline depth observed from the El Niño-Southern Oscillation (ENSO) events in the tropical Pacific Ocean (McPhaden 2004) or the IOP events (Saji et al. 1999; Webster et al. 1999; Yu and Rienecker 1999). In most tropical oceans, convergence of warm water downwelling waves is a predominant contributor to buoyancy, because the effect of salinity is generally negligible. However, the Bay of Bengal is a very special region where the sea surface water is fresh and also has large horizontal gradient with low salinity $(<31 \mathrm{psu})$ in the north and higher salinity $(>34 \mathrm{psu})$ in the south; the convergence of fresh surface water is more dominant than the surface heating in changing BC. In other words, SSHA is a depth integration of the buoyancy/ density profile of the water column. The exact relationship between SSHA and the thermocline depends on whether the effect of temperature on buoyancy outweighs the effect of salinity.

We also computed the contribution of salinity versus temperature to SSHA variability at the $15^{\circ} \mathrm{N}, 90^{\circ} \mathrm{E}$ buoy location, by using a 11/2-layer model (Fig. 11a) similar to the one used by $\mathrm{Yu}$ (2003). This model configuration is used here to examine the hydrostatic relationships, not to run numerical experiments. In the $1 \frac{1}{2} 2$-layer model concept, a dynamically active upper layer with density $\rho_{1}$ is above an infinitely deep motionless layer with slightly higher density $\rho_{2}$. The interface between the two layers represents the pycnocline. Different from most applications of the $1 \frac{1}{2}$-layer model that assume $\rho_{1}$ and $\rho_{2}$ are constant, here $\rho_{1}$ is allowed to vary with temperature and salinity, whereas the lower-layer density $\rho_{2}$ is held (a)

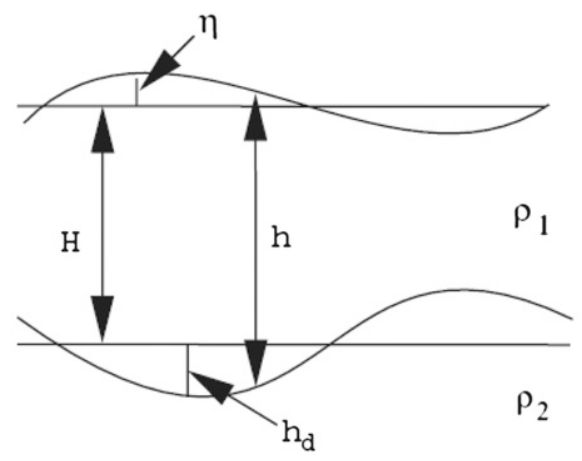

(b)

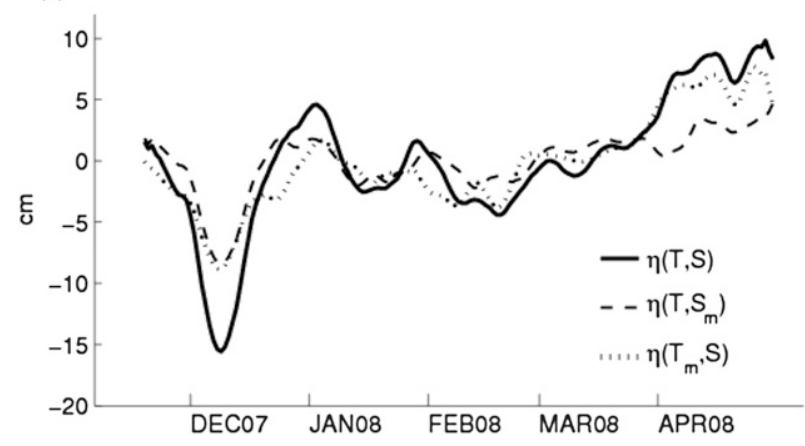

FIG. 11. (a) Schematic diagram of a two-layered system used to approximate the sea level variability based on the upper-ocean density structure. (b) The sea level variability produced under three scenarios: $\eta(T, S)$ is produced from ExpI, which uses observed temperature and salinity; $\eta\left(T, S_{m}\right)$ is produced from ExpII, which uses observed temperature and time-mean salinity profile; and $\eta\left(T_{m}, S\right)$ is produced from ExpIII, which uses observed salinity and time-mean temperature profile.

constant. By doing so, the effects of salinity versus temperature on sea level variability can be examined separately. Following Yu (2003), the relationship between the sea level variability $\eta^{\prime}(t)$ and the variability of the pycnocline depth $h_{d}^{\prime}(t)$ is approximated as

$$
\eta^{\prime}(t) \approx-\frac{\rho_{1}^{\prime}(t)}{\overline{\rho_{1}}} H+\frac{\rho_{2}-\overline{\rho_{1}}}{\rho_{2}} h_{d}^{\prime}(t)
$$

where the bar denotes the temporal mean and the prime denotes the departure from the mean. The mean pycnocline depth is denoted by $H$. The first term on the right-hand side of Eq. (1) represents the effect of the density perturbation on the sea level variability, and the second term is the effect of the interfacial displacement. If $\rho_{1}^{\prime}$ is small and can be neglected, then $\eta^{\prime}(t)$ is determined by the second term. This yields the commonly used relationship between the sea level and pycnocline variability in the layer models.

The total measurement time is slightly more than 5 months, so the mean values (e.g., $H$ and $\overline{\rho_{1}}$ ) in Eq. (1) are computed as the time mean of the entire 
measurement period. As is seen from Fig. $6 c$, the depth of $22.4 \sigma_{t}$ is a good proxy of the pycnocline; hence, $\rho_{1}$ is calculated by averaging the observed temperature and salinity from the surface to the depth of $22.4 \sigma_{t}$. The experiment thus obtained is named ExpI. To examine the relative contribution of salinity and temperature to $\eta^{\prime}$, two additional experiments, named ExpII and ExpIII, are conducted. ExpII is designed to test the thermal effect so that $\rho_{1}$ is constructed from observed daily temperature profiles with the salinity profile held as the 5-month mean, whereas ExpIII is to test the salinity effect so that $\rho_{1}$ is constructed from observed daily salinity profiles with the temperature profile held as the 5-month mean. The resulting $\eta^{\prime}$ from the three experiments is displayed in Fig. 11b, which shows that, compared to ExpII (variable temperature), ExpIII (variable salinity) has a better agreement with ExpI. Because density and buoyancy are related and both are a measure of the stratification of the water column, it is not a surprise to see that Fig. 11b carries the similar message as Fig. $9 \mathrm{~b}$ in that salinity has a bigger role than temperature in controlling the sea level variability in the Bay of Bengal. In particular, the rapid increase of the sea level during March-April 2008, associated with passage of downwelling Rossby waves, was controlled more predominantly by salinity anomalies.

\section{Discussion and summary}

Using observations acquired from the $15^{\circ} \mathrm{N}, 90^{\circ} \mathrm{E}$ RAMA buoy together with basin-scale Argo profiling floats and a constellation of earth observing satellites, an in-depth data analysis was conducted to gain understanding of the occurrence of a high SST front in the warm, fresh, and highly stratified upper ocean of the Bay of Bengal in April-May 2008. The development of this SST front preceded the formation of Cyclone Nargis, which changed its course after encountering the front and tracked along it until landfall. One unique feature of this high SST front was its coupling with high SSHA, which is unusual for a basin where SST is normally uncorrelated with SSHA. Our study proposes that the interaction between downwelling Rossby waves and surface fresh waters is a key mechanism for the SST-SSHA coupling observed during this period.

It is evident from the observations that the SST front resulted from the westward-propagating downwelling Rossby waves originating at the eastern boundary of the Bay of the Bengal about 4 months earlier. The westward phase speed of SSH and associated SST variability was of $\sim 9 \mathrm{~cm} \mathrm{~s}^{-1}$ at $15^{\circ} \mathrm{N}$, comparable to the phase speed of first baroclinic Rossby waves. It is known that Rossby waves at the eastern boundary are generated either by local alongshore monsoon winds or by remote forcing through radiation of coastal Kelvin waves that propagate from the equator. Remote equatorial forcing was the most likely origin of these waves as inferred from model simulations (not shown).

The Bay of Bengal is a very special region where the halocline is especially strong and where the near-surface salinity field exhibits a large gradient, with lower salinity $(<31 \mathrm{psu})$ in the northeast and higher salinity $(>34 \mathrm{psu})$ in the southwest. The fresher sea surface in the northern bay is predominantly due to the freshwater inflows from rivers and less to precipitation. At the buoy location, freshening of the near-surface layer occurred when surface currents associated with downwelling Rossby waves had a westward and/or southward component. These currents advected the fresher waters from the northeast and reduced the salinity of the surface waters at the buoy site. Horizontal convergence of fresh surface waters increased the buoyancy of the upper layer and caused the mixed layer to become very shallow. The surface heating trapped within the thin mixed layer caused the layer to warm, whereas the increase in buoyancy from low salinity enhanced the high SSHA associated with downwelling Rossby waves. Thus, high SST coincided with high SSHA. The processes governing the relationship between SST and SSHA in association with downwelling Rossby waves are summarized in a schematic diagram in Fig. 12.

Computation of buoyancy content in the upper layer shows a higher correlation with salinity content than with heat content. Examination of the relative contribution of salinity versus temperature on sea level variability was also conducted by using buoy temperature/ salinity observations and a relationship derived from a 1/1/2-layer hydrostatic model configuration. Consistent with the computation of buoyancy content, sea level variability in the Bay of Bengal is controlled predominantly by near-surface freshening and only weakly by near-surface warming. In particular, the rapid increase of SSHA associated with downwelling Rossby waves was governed primarily by salinity anomalies.

The close relationship between SSHA and halocline variability in the bay is in striking contrast to the widely known correlation between SSHA and the thermocline depth observed from the ENSO or IOP events in the tropical oceans, where temperature has a dominant effect on buoyancy. This suggests that the relationship between SSHA and thermocline depth depends on whether the effect of temperature on buoyancy outweighs the effect of salinity. In the Bay of Bengal, the near-surface layer is so fresh that salinity impacts the near-surface density profile more than temperature, decoupling SSHA from thermocline variability. 


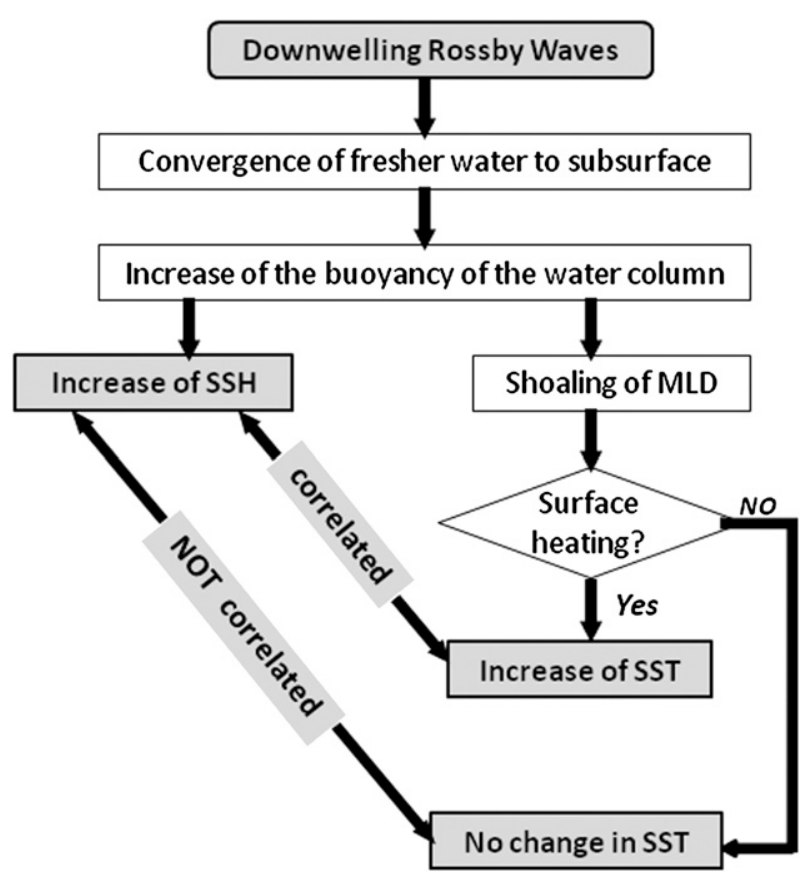

FIG. 12. Schematic diagram of the coupling between downwelling Rossby waves and surface fresh waters in producing the observed SST-SSHA relationships.

The weak relationship between high SSHAs and heat content has important implications for computing hurricane heat potential from SSHA in the Bay of Bengal. Hurricane heat potential is a measure of the heat content between the sea surface and the depth of the $26^{\circ} \mathrm{C}$ isotherm. The index is useful for identifying warm anticyclonic features to monitor regions of very high hurricane heat potential, because hurricanes often undergo sudden intensification over these regions (Shay et al. 2000). In the western tropical Atlantic and the Gulf of Mexico, SSHA variability is closely related to the changes in the depth of the main thermocline. Therefore, the hurricane heat potential is commonly computed from the altimeter-derived vertical temperature profile estimates (Shay et al. 2000; Goni and Trinanes 2003). This study shows that caution should be exercised when applying these procedures to the Bay of Bengal, because the correlation between SSHA and heat content can be low because of salinity effects. However, the good correlation between high SSHA and high SST as found in our study suggests that SSHA could still be a good indicator for cyclone development, even if not directly connected to high tropical cyclone heat potential in the traditional sense.

Cyclone Nargis is one of the best ever observed tropical storm in the Bay of Bengal. The recently implemented IndOOS program provided this study the needed subsurface measurements for a detailed examination of upper-ocean conditions before and during Nargis. The occurrence of the SST front associated with the passage of downwelling Rossby waves and the interaction of the wave with low-salinity surface waters to produce the unusual SST-SSHA coupling are unique features identified by this study. The generality of these oceanic features for other storm events in the bay is not yet known. Further research is needed to gain a clearer understanding of the ocean state associated with cyclone development in the bay.

Acknowledgments. This work was supported by the NOAA/Office of Climate Observation (OCO) program. L. Yu thanks John Toole for stimulating discussions. We sincerely thank Lynne Talley and two anonymous reviewers for constructive reviews that led to significant improvements in the manuscript. The authors acknowledge the TAO project office of NOAA/PMEL for providing RAMA buoy measurements, NASA GPCP for the daily precipitation product, Argo JAMSTEC for the gridded monthly salinity product, AVISO for the weekly SSHA product, and NOAA/OISST for the daily SST product.

\section{REFERENCES}

Alam, M. M., M. A. Hossain, and S. Shafee, 2003: Frequency of Bay of Bengal cyclonic storms and depressions crossing different coastal zones. Int. J. Climatol., 23, 1119-1125.

Ali, M. M., P. S. V. Jagadeesh, and S. Jain, 2007: Effects of eddies on Bay of Bengal cyclone intensity. Eos, Trans. Amer. Geophys. Union, 88, 93-94.

AVISO, 2009: Ssalto/Duacs user handbook: (M)SLA and (M)ADT near-real time and delayed time products. CNES Rep. CLS-DOS-NT-06.034, 51 pp.

Eigenheer, A., and D. Quadfasel, 2000: Seasonal variability of the Bay of Bengal circulation inferred from TOPEX/Poseidon altimeter. J. Geophys. Res., 105, 3243-3252.

Emanuel, K. A., 1999: Thermodynamic control of hurricane intensity. Nature, 401, 665-669.

Girishkumar, M. S., M. Ravichandran, M. J. McPhaden, and R. R. Rao, 2011: Intraseasonal variability in barrier layer thickness in the south central Bay of Bengal. J. Geophys. Res., 116, C03009, doi:10.1029/2010JC006657.

Godfrey, J. S., and E. J. Lindstrom, 1989: The heat budget of the equatorial west Pacific surface mixed layer. J. Geophys. Res., 94, 8007-8017.

Goni, G. J., and J. A. Trinanes, 2003: Ocean thermal structure monitoring could aid in the intensity forecast of tropical cyclones. Eos, Trans. Amer. Geophys. Union, 84, doi:10.1029/ 2003EO510001.

Gopalan, A. K. S., V. V. Gopalakrishna, M. M. Ali, and R. Sharma, 2000: Detection of Bay of Bengal eddies from TOPEX and in situ observations. J. Mar. Res., 58, 721-734.

Gray, W. M., 1979: Hurricanes: Their formation, structure and likely role in the tropical circulation. Quart. J. Roy. Meteor. Soc., 105, 155-218.

Han, W., and J. P. McCreary, 2001: Modeling salinity distributions in the Indian Ocean. J. Geophys. Res., 106, 859-877. 
Hosoda, S., T. Ohira, and T. Nakamura, 2008: A monthly mean dataset of global oceanic temperature and salinity derived from Argo float observations. JAMSTEC Rep. Res. Dev., 8, 47-59.

Huffman, G. J., R. F. Adler, M. M. Morrissey, D. T. Bolvin, S. Curtis, R. Joyce, B. McGavock, and J. Susskind, 2001: Global precipitation at one-degree daily resolution from multisatellite observations. J. Hydrometeor., 2, 36-50.

Kikuchi, K., B. Wang, and H. Fudeyasu, 2009: Genesis of tropical cyclone Nargis revealed by multiple satellite observations. Geophys. Res. Lett., 36, L06811, doi:10.1029/2009GL037296.

Lin, I.-I., C.-H. Chen, I.-F. Pun, W. T. Liu, and C.-C. Wu, 2009: Warm ocean anomaly, air sea fluxes, and the rapid intensification of tropical cyclone Nargis (2008). Geophys. Res. Lett., 36, L03817, doi:10.1029/2008GL035815.

Longshore, D., 2008: Encyclopedia of Hurricanes, Typhoons, and Cyclones. Checkmark, 468 pp.

Lukas, R., and E. Lindstrom, 1991: The mixed layer of the western equatorial Pacific. J. Geophys. Res., 96, 3343-3357.

McCreary, J. P., P. K. Kundu, and R. L. Molinari, 1993: A numerical investigation of the dynamics, thermodynamics and mixed-layer processes in the Indian Ocean. Prog. Oceanogr. 31, 181-244.

McPhaden, M. J., 2004: Evolution of the 2002/03 El Niño. Bull. Amer. Meteor. Soc., 85, 677-695.

_ - and Coauthors, 2009a: Ocean-atmosphere interactions during cyclone Nargis. Eos, Trans. Amer. Geophys. Union, 90, doi:10.1029/2009EO070001.

_ - and Coauthors, 2009b: RAMA: The Research Moored Array for African-Asian-Australian Monsoon Analysis and Prediction. Bull. Amer. Meteor. Soc., 90, 459-480.

Meyers, G., and R. Boscolo, 2006: The Indian Ocean Observing System (IndOOS). CLIVAR Exchanges, No. 39, International CLIVAR Project Office, Southampton, United Kingdom, 2-3.

Moore, D. W., 1968: Planetary-gravity waves in an equatorial ocean. Ph.D. thesis, Harvard University, 201 pp.

Potemra, J. T., M. E. Luther, and J. J. O'Brien, 1991: The seasonal circulation of the upper ocean in the Bay of Bengal. J. Geophys. Res., 96, 12 667-12 683.

Rao, R. R., and R. Sivakumar, 1996: Seasonal variability of nearsurface isothermal layer and thermocline characteristics of the tropical Indian Ocean. Meteor. Atmos. Phys., 61, 201-212.

Rao, S. A., and S. K. Behera, 2005: Subsurface influence on SST in the tropical Indian Ocean: Structure and interannual variability. Dyn. Atmos. Oceans, 39 (1-2), 103-135, doi:10.1016/ j.dynatmoce.2004.10.014.

_ - V. V. Gopalakrishna, S. R. Shetye, and T. Yamagata, 2002: Why were cool SST anomalies absent in the Bay of Bengal during the 1997 Indian Ocean Dipole Event? Geophys. Res. Lett., 29, 1555, doi:10.1029/2001GL014645.

Reale, O., W. K. Lau, J. Susskind, E. Brin, E. Liu, L. P. Riishojgaard, M. Fuentes, and R. Rosenberg, 2009: AIRS impact on the analysis and forecast track of tropical cyclone Nargis in a global data assimilation and forecasting system. Geophys. Res. Lett., 36, L06812, doi:10.1029/2008GL037122.

Reynolds, R. W., T. M. Smith, C. Liu, D. B. Chelton, K. S. Casey, and M. G. Schlax, 2007: Daily high-resolution blended analyses for sea surface temperature. J. Climate, 20, 5473 5496.

Saji, H. N., B. N. Goswamy, P. N. Vinayachandran, and T. Yamaghata, 1999: A dipole mode in the tropical Indian Ocean. Nature, 401, 360-363.
Schott, F., and J. P. McCreary, 2001: The monsoon circulation of the Indian Ocean. Prog. Oceanogr., 51, 1-123.

Sengupta, D., and M. Ravichandran, 2001: Oscillations of Bay of Bengal sea surface temperature during the 1998 Summer Monsoon. Geophys. Res. Lett., 28, 2033-2036.

- , P. K. Ray, and G. S. Bhat, 2002: Spring warming of the eastern Arabian Sea and Bay of Bengal from buoy data. Geophys. Res. Lett., 29, 1734, doi:10.1029/2002GL015340.

Shay, L. K., G. J. Goni, and P. G. Black, 2000: Effect of a warm ocean ring on Hurricane Opal. Mon. Wea. Rev., 128, 13661383.

Shetye, S. R., A. D. Gouveia, D. Shankar, S. S. C. Shenoi, P. N. Vinayachandran, D. Sundar, G. S. Michael, and G. Nampoothiri, 1996: Hydrography and circulation in the western Bay of Bengal during the northeast monsoon. J. Geophys. Res., 101, 14 01114025 .

Sprintall, J., and M. Tomczak, 1992: Evidence of barrier layer in the surface layer of tropics. J. Geophys. Res., 97, 73057316.

Thadathil, P., P. M. Muraleedharan, R. R. Rao, Y. K. Somayajulu, G. V. Reddy, and C. Revichandran, 2007: Observed seasonal variability of barrier layer in the Bay of Bengal. J. Geophys. Res., 112, C02009, doi:10.1029/2006JC003651.

Varkey, M. J., V. S. N. Murty, and A. Suryanarayana, 1996: Physical oceanography of the Bay of Bengal and Andaman Sea. Oceanography and Marine Biology: An Annual Review, A. Ansell and M. Barnes, Eds., Vol. 34, 1-70.

Vinayachandran, P. N., S. R. Shetye, D. Sengupta, and S. Gadgil, 1996: Forcing mechanisms of the Bay of Bengal circulation. Curr. Sci., 71, 753-763.

— V. S. N. Murty, and V. R. Babu, 2002: Observations of barrier layer formation in the Bay of Bengal during summer monsoon. J. Geophys. Res., 107, 8018, doi:10.1029/2001JC000831.

Webster, P. J., 2008: Myanmar's deadly “daffodil.” Nat. Geosci., 1, 488-490.

— A. Moore, J. Loschnigg, and M. Leban: 1999: Coupled oceanatmosphere dynamics in the Indian Ocean during 1997-98. Nature, 401, 356-360.

Yamada, H., Q. Moteki, and M. Yoshizaki, 2010: The unusual track and rapid intensification of Cyclone Nargis in 2008 under a characteristic environmental flow over the Bay of Bengal. J. Meteor. Soc. Japan, 88, 437-453.

Yang, J., L. Yu, C. Koblinsky, and D. Adamec, 1998: Dynamics of the seasonal variations in the Indian Ocean from TOPEX/POSEIDON sea surface height and an ocean model. Geophys. Res. Lett., 22, 1915-1918.

Yaremchuk, M., Z. Yu, and J. McCreary, 2005: River discharge into the Bay of Bengal in an inverse ocean model. Geophys. Res. Lett., 32, L16605, doi:10.1029/2005GL023750.

$\mathrm{Yu}, \mathrm{L} ., 2003$ : Variability of the depth of the $20^{\circ} \mathrm{C}$ isotherm along $6^{\circ} \mathrm{N}$ in the Bay of Bengal: Its response to remote and local forcing and its relation to satellite SSH variability. Deep-Sea Res. II, 50, 2285-2304.

—_ and M. Rienecker, 1999: Mechanisms for the Indian Ocean warming during 1997-98 El Niño. Geophys. Res. Lett., 26 (6), 735-738.

- J. J. O'Brien, and J. Yang, 1991: On the remote forcing of the circulation in the Bay of Bengal. J. Geophys. Res., 96, 20 44920454.

- X. Jin, and R. A. Weller, 2007: Annual, seasonal, and interannual variability of air-sea heat fluxes in the Indian Ocean. J. Climate, 20, 3190-3209. 